\title{
Funding the future
}

\author{
David L. Ortiz* \\ College of Human Medicine, Michigan State University, East Lansing, MI, USA
}

*Corresponding author: David Ortiz; ortizdav@msu.edu

Earlier this year, 3 days before the vernal equinox, my classmates and I gathered at the ballroom of the Michigan State University Club to learn about our placement in the 2013 Match (National Residency Matching Program - a program which annually assigns medical school graduates to residency positions). When the clock struck noon, we tore into white envelopes revealing the destination of the next 3-5 years of our lives. The room was abuzz with excitement, cheers, and tears as we shared this life-changing moment with one another. We had all matched, most of us to our top programs. Now we could finally breathe a sigh of relief as the anxious uncertainty about whether we would continue on our medical journeys melted away.

Unfortunately, this was not the case for every graduate in the United States this year. In fact, 2,076 of this year's graduating US seniors failed to match and entered the Supplemental Offer and Acceptance Program (SOAP - a secondary residency assignment program for those that fail to find a spot in the primary Match). After the SOAP, 528 US seniors remained completely unmatched, more than twice the number in that position in 2012. ${ }^{1}$ SOAP was introduced in 2012, so no comparable data are available on the number of unmatched seniors prior to 2012. What is known is that this March, hundreds of US medical students found themselves with an average debt of $\$ 170,000$, with no residency position to help them.

This is a problem that is expected to get worse, not better. The number of graduates is increasing every year, while the number of residency slots is not keeping pace. The reasons for this are multifactorial. To better understand why, it would be helpful to look back at the history of medical education policy.

How shall the Nation be supplied with adequate numbers of well-qualified physicians?

$$
\text { - The Bane Report }{ }^{2}
$$

In 1959, the US Public Health Service, under the leadership of Frank Bane, the Surgeon General's consultant, assessed the ability of US medical training to produce the number of physicians needed for the growing population. This came to be known as the Bane Report, and it predicted a deficiency of wellqualified physicians, if the number of medical students was not increased. The resulting government subsidies $^{3}$ would double the number of graduates over the next 23 years: from 6,900 in 1959 to 14,144 in $1982 .{ }^{4}$

This growth came to a halt in 1981, after the Graduate Medical Education National Advisory Committee (GMENAC) projected a surplus of 145,000 physicians by the year $2000 .^{5}$ To discourage further expansion of medical schools, congress slashed their subsidies. The intended results were achieved, and medical school enrollment remained frozen at the 1982 levels of about 16,000 freshmen per year. Enrollment would remain at this level until $2005 .^{4}$

Despite the suspension of medical school growth, the total number of physicians in America continued to rise for at least two reasons: First, because medical training takes 7-10 years, it has been estimated that the effects of increasing medical school enrollment are not appreciated for 10-20 years, and the full effects may not be realized for 30-40 years, ${ }^{6}$ when older physicians retire and are replaced. Therefore, it is conceivable that the effects of ceasing medical school growth in 1981 might not be noticed until 1991-2001. Second, the introduction of the Medicare Prospective Payment System in 1983 provided incentives for hospitals to raise the number of residency slots far above the number of US grads. ${ }^{7}$ This led to an influx of thousands of international medical graduates (IMG), who increased the supply of physicians in the United States, ${ }^{4}$ independent of medical school enrollment. ${ }^{8}$ As a response to continued growth in the physician workforce, the Balanced Budget Act capped the number of residency positions in 1997, in an effort to reduce both cost and physician excess.

In 2006, the tides shifted, and the Association of American Medical Colleges (AAMC) projected a shortage - not surplus - of 90,000 physicians by 2020 . The AAMC then prompted US medical schools to raise 
enrollment by $30 \%$, from 16,488 in 2002 to 21,434 by $2016 .^{9}$ Medical schools across the country responded to this call with increased enrollment, and in the 20122013 academic year, enrollment had reached 19,517. Furthermore, by 2012, 12 new medical schools received accreditation from the Liaison Committee on Medical Education and seven others had started the accreditation process. With the increased enrollment in existing medical colleges and the addition of new schools, the AAMC expects the goal of $30 \%$ growth to be achieved by 2016 . After this, they have projected that enrollment should remain stable at around 21,500 for the foreseeable future. ${ }^{9}$

\section{THE CURRENT STATE OF AFFAIRS}

Currently, despite the imminent projected physician shortage, the cap on residency positions initiated in 1997 remains in place. It is true that even without increased federal funding, there has been some growth in the total number of accredited residents, an (increase of $15 \%$, or 15,000 residents, between 2000 and 2010), ${ }^{10}$ and we can identify several reasons for this. First, with every institution required to commit to an all-or-nothing listing of its programs in the Match, several thousand residency positions are now listed for the first time. ${ }^{11}$ Second, multiple acts - most notably the Medicare Modernization Act of $2003^{12}$ - have redistributed unused residency positions, increasing the number of residents by $4,500-6,000 .{ }^{13}$ Third, a handful of new residency programs have been funded federally through non-Medicare acts, such as the Affordable Care Act. ${ }^{14}$ Finally, several state hospitals and private groups have chosen to take on the costs of training residents themselves, and they have increased their resident count above the 1997 cap without federal funding. ${ }^{15-18}$

Nevertheless, while these measures have been able to raise the availability of residency positions above the federal cap, we are still projected to face a shortage of 90,000 physicians by 2020 due largely to limited residency slots. This shortage has been exacerbated by the Affordable Care Act, which is estimated to have increased the need for physicians by approximately $30,000,{ }^{19}$ while only raising the number of federally funded residency spots by about $300 .^{20}$

Further worsening the situation is a push for reduction - not increase - in federal funding for graduate medical education (GME). Part of this is due to the lack of GME-labeled fund transparency. After money is transferred to healthcare facilities, it is nearly impossible to track whether it is actually used for its intended purpose of training residents. As a result, it is difficult to estimate the difference (positive or negative) between GME funds and resident costs on hospitals in order to determine whether the amount of funding is appropriate. ${ }^{21}$ Accordingly, GME payments have often been the target of cuts in recent years. For example, last month President Obama announced the FY 2014 budget, which included \$11B (about 10\% of the total 10-year budget) in GME cuts over the next 10 years, to 'Better align GME payments with patient care costs'. ${ }^{22}$

\section{HOW DO WE PAY FOR THIS?}

One day prior to the 2013 Match, two bills were presented in congress: H.R. 1201: Training Tomorrow's Doctors Today Act, ${ }^{23}$ and H.R. 1180: Resident Physician Shortage Reduction Act of 2013. ${ }^{24}$ These bills would raise the federal cap on residency positions by 15,000 over the next 5 years. While these proposals were lauded by the AAMC, ${ }^{25}$ such an increase has previously been estimated to only address about $30 \%$ of the expected physician shortage. ${ }^{20}$ Unfortunately, the outlook for each of these bills is unfavorable. Similar proposals have been made in the past 2 years, without success, ${ }^{26,27}$ and this year's bills currently have very little support in the House. ${ }^{23,24}$

Given the apparent federal opposition to increased funding of GME, some researchers have explored the possible outcomes of cutting GME funding. One analyst estimated that a $10 \%(\$ 600 \mathrm{M})$ cut in indirect medical education payments would result in a reorganizing, but overall negligible change in the number of residency positions. ${ }^{21}$ In another study, a survey of $70 \%$ of all US residency and fellowship programs revealed that a 33\% reduction in GME funding would result in an overall reduction of 19,879 ( $18 \%$ of all) residency and fellowship positions. A $50 \%$ reduction would cause a loss of $33,023(29 \%)$ positions. ${ }^{28}$

Should a $33-50 \%$ cut come to pass, programs most commonly reported that they would look to private funding for ongoing support. ${ }^{28}$ Such funding already exists in many places in the country. In Utah, Texas, and New York, non-profit hospitals and councils have contributed to the creation of hundreds of new residency programs. ${ }^{16}$ Pharmaceutical companies have also stepped in to foot the bill for residency slots in fields expected to 'pay back' over time, such as dermatology. ${ }^{18}$ Other organizations work with hospitals to fund the creation of medical residency slots for sponsored IMG. ${ }^{17}$ Finally, an often-neglected source of funding is insurance providers. In the past year, the Center for American Progress, a progressive think tank, 
called on private insurers to contribute to residency funding. ${ }^{29}$ Other groups have stated that private insurers, who pay more per visit than Medicare does on average, are already contributing toward GME funding, albeit indirectly. ${ }^{21,30}$

\section{CONCLUSIONS}

The problems facing healthcare training today are not simple. Predictions about future demand for physicians have a poor track record, as the GMENAC studies of the 1980s showed. Even if one could predict perfectly the demand for physicians in the future, history has shown that it takes $10-40$ years for the full effects of increased medical school enrollment to be felt. Increased enrollment of medical students will not necessarily result in meeting our nation's healthcare needs. As physician attitudes change with a new generation that places a higher value on quality of life, and personal time, total physician work hours may fall even if the number of physicians rises. Finally, the current cap on federally funded residency positions may stifle the effects of higher medical student enrollment.

These are a few closing thoughts I want to leave you with:

The rate of GME must rise. In its present state, GME could sustain reductions as great as $10 \%$ of funding without the loss of total residency slots, but any decrease in GME funding will undoubtedly perpetuate the inadequacy of the physician workforce. By 2016, without increased GME funding, there will be a substantial increase in the number of unmatched US seniors and a substantial decrease in the number of foreign medical grads. Unfortunately, current trends in healthcare policy and attitudes suggest lack of appreciation for the need for new residency positions by both the government and the public. There is broad public support for increasing the number of medical students, but comparatively less enthusiasm for raising the number of residents. If we want to change the direction of public allocation of residency funds, then we will need to raise public awareness of this problem.

If the federal government is unable to resolve the projected discordance between increasing physician shortages and decreasing federal supply, we may see a future where an increasing number of training positions are either eliminated, or funded through alternative channels. It begs the question: Why do the majority of residency slots need to be funded by the government? Private insurers, who already pay more than Medicare for the same procedures, could desig- nate that a particular percentage of hospital reimbursements be contributed directly to residency training, when a resident is involved in a patient's care. Such earmarking could create more transparency in hospital payments and allow private insurers to receive credit for the funds they already contribute toward GME. Private and state hospital systems, and private organizations are also ready to fund expansions in residency, but again, public and professional support for such measures is needed to effect change.

When asked by a reporter from the State News as to how I felt about my Match results, I replied with relief that finally 'We can start looking for a new place to live in (and) start looking into what we're going to do as a family. Everything changes today'. ${ }^{31}$ It is an uncertain future that I and the other 2013 College of Human Medicine (CHM) graduates face in the field of medicine, but we can take solace in knowing where we are going for the next few years, at least. I hope that next year's class can say the same.

Conflict of interest and funding: The author has not received any funding or benefits from industry or elsewhere to conduct this study.

\section{REFERENCES}

1. National Resident Matching Program. NRMP post-match press release. Washington, DC: National Resident Matching Program; 2013.

2. Education USSGCG on M, Bane F. Physicians for a growing America: report. Washington, DC: Public Health Service, U.S. Department of Health, Education, and Welfare; 1959.

3. Ruhe CW. 1966. Present projections of physician production. Chicago, IL: American Medical Association Council on Medical Education. http://dx.doi.org/10.1001/jama.1966.03110230110024. 4. National Residency Matching Program. Results and data: 2012 main residency match ${ }^{\mathrm{SM}}$. Washington, DC: National Residency Matching Program; 2012.

5. Health Resources Administration, Office of Graduate Medical Education. Report of the Graduate Medical Education National Advisory Committee, Volumes I-VII. Washington, DC: Health Resources Administration, Office of Graduate Medical Education; 1980.

6. Nicholson S. Will the United States have a shortage of physicians in 10 years? 2009. Available from: http://hdl. handle.net/1813/15101. Accessed May 1, 2013.

7. Office of Inspector General. Medicare hospital prospective payment system - how DRG rates are calculated and updated; Washington, DC: U.S. Department of Health \& Human Services; 2001.

8. Reinhardt UE. 2002. Analyzing cause and effect in the U.S. physician workforce. Health Aff (Millwood) 21(1):165-6. 
9. Center for Workforce Studies. Results of the 2011 Medical School Enrollment Survey. Washington, DC: Association of American Medical Colleges; 2011.

10. Center for Workforce Studies. 2011 State physician workforce data book. Washington, DC: Association of American Medical Colleges; 2011.

11. National Resident Matching Program. NRMP residency match 2013 results. Washington, DC: National Resident Matching Program; 2013.

12. Medicare Prescription Drug, Improvement, and Modernization Act of 2003 (2003H.R. 1). GovTrack.us. Available from: http://www.govtrack.us/congress/bills/108/hr1 [cited 15 May 2013].

13. Chen C, Xierali I, Piwnica-Worms K, Phillips R. 2013. The redistribution of graduate medical education positions in 2005 failed to boost primary care or rural training. Health Aff (Millwood) 32(1):102-10. http://dx.doi.org/10.1377/hlthaff.2012.0032. 14. Local hospital CEOs want private fund for more residencies - Jacksonville Business Journal. Available at: http://www.bizjournals.com/jacksonville/print-edition/2011/ 11/18/local-hospital-ceos-want-private-fund.html?page =all [cited 6 May 2013].

15. Sheri P. Federal dollars launch National Family Medicine Residency Program - AAFP News Now - AAFP. AAFP. Available at: http://www.aafp.org/online/en/home/ publications/news/news-now/education-professionaldevelopment/20130307ntlfmresidency.html. Accessed May 6, 2013.

16. Innovative funding opens new residency slots amednews.com; 2006. Available from: http://www. amednews.com/article/20060130/profession/301309963/2/ \#minb [cited 1 May 2013].

17. Privately Funded Residency. AmeriClerkships.org; 2013. Available from: http://americlerkships.org/mentors/services2/privately-funded-residency. Accessed May 13, 2013. 18. Oransky I. How much for that dermatologist in the window? Slate; 2005. Available from: http://www.slate.com/ articles/health_and_science/medical_examiner/2005/06/ how_much_for_that_dermatologist_in_the_window.html [cited 15 May 2013].

19. Kirch DG, Henderson MK, Dill MJ.. 2012. Physician workforce projections in an era of health care reform. Annu Rev Med 63(1):435-45. http://dx.doi.org/10.1146/ annurev-med-050310-134634.
20. Association of American Medical Colleges. AAMC physician workforce policy recommendations. Washington, DC: Association of American Medical Colleges; 2012.

21. Rye B. 2012. Assessing the impact of potential cuts in medicare doctor-training subsidies. Washington, DC: Bloomberg Government.

22. Office of Management and Budget. Fiscal year 2014 budget of the U.S. Government. Washington, DC: U.S. Government Printing Office; 2013.

23. Training Tomorrow's Doctors Today Act (H.R. 1201). GovTrack.us. Available from: http://www.govtrack.us/ congress/bills/113/hr1201 [cited 1 May 2013].

24. Resident Physician Shortage Reduction Act of 2013 (H.R. 1180). GovTrack.us. Available from: http://www.govtrack.us/ congress/bills/113/hr1180 [cited 1 May 2013].

25. Association of American Medical Colleges. House bill would increase residency positions, ease doctor shortage. Available from: https://www.aamc.org/newsroom/ newsreleases/330948/031413.html [cited 15 May 2013]. 26. Resident Physician Shortage Reduction Act of 2011 (2011S. 1627). GovTrack.us. Available from: http://www. govtrack.us/congress/bills/112/s1627 [cited 15 May 2013]. 27. Resident Physician Shortage Reduction and Graduate Medical Education Accountability and Transparency Act (2012H.R. 6352). GovTrack.us. Available from: http://www. govtrack.us/congress/bills/112/hr6352 [cited 15 May 2013]. 28. Nasca TJ, Miller RS, Holt KD.. 2011. The potential impact of reduction in federal GME funding in the United States: a study of the estimates of designated institutional officials. J Grad Med Educ 3(4):585-90. http://dx.doi.org/10.4300/

JGME-03-04-33.

29. The Center for American Progress Health Policy Team. The senior protection plan. Washington, DC: Center for American Progress; 2012.

30. Wynn B, Guarino C, Morse L, Cho M. 2006. Alternative ways of financing graduate medical education.

31. Wan J. Medical students celebrate being paired with hospitals. The State News. Available from: http://statenews. com/article/2013/03/medical-students-celebrate-beingpaired-with-hospitals. Published March 2013. [cited 15 May 2013]. 